\title{
The Novel Corona Virus Infection (COVID-19)
}

\author{
Harshal Vilas Bhonde, Manju Chandankhede and Swarupa Chakole \\ ${ }^{1}$ First year MBBS Student at Datta Meghe Medical College, Nagpur, India \\ ${ }^{2}$ Department of Biochemistry Datta Meghe Medical College, Shalinitai Meghe \\ Hospital and Research Centre, Nagpur, India \\ ${ }^{3}$ Department of Community Medicine Jawaharlal Nehru Medical College, Datta Meghe \\ Institute of Medical Sciences Sawangi (Meghe), Wardha, India \\ Corresponding author email:drmanjusc@gmail.com
}

\section{ABSTRACT}

COVID-19 (coronavirus 2019) has recently been identified as a coronavirus that is thought to have developed as a genetically modified zoonotic virus. 2019 novel corona virus virus) The outbreak started in China but has since spread to many other countries; was officially declared by the WHO as pandemic1 on March 11, 2020. Although coronavirus 2019 (COVID-19) is suspected to have originated in a human animal (zoonotic origin) followed by human-to-human transmission, other lines should not be excluded. Compared to infections caused by previously known human CoVs, COVID-19 shows a small formation of pathogenesis but has a high transmission capacity, as evidenced by the increasing number of confirmed cases worldwide. Compared to other emerging viruses, such as the Ebola virus, Avian H7N9, SARS$\mathrm{CoV}$, and Middle East respiratory coronavirus (MERS-CoV), SARS-CoV-2 has been shown to have low pathogenicity and is equally accessible. The following is a summary of current HIV information for SARS 2: First, emerging pneumonia, COVID-19, caused by the SARS corona 2 virus, has a higher rate of infection but is less severe than SARS and MERS in relation to illness and death. Second, people with disabilities include older people and others who need special care and treatment because of their health status.

\section{KEY WORDS: CORONA VIRUS, DIAGNOSIS, PHYSICAL EXAMINATION, TREATMENT.}

\section{INTRODUCTION}

The 2019 corona virus or SARSCoV-2 as it is called, is spreading rapidly from its origins in Wuhan City of China to the rest of the world. SARSCoV-2 is a straightforward, single-line RNA virus. The SARS-CoV-2 virion is $50-$ $200 \mathrm{~nm}$ wide and has four abstract proteins: spike (S), envelope (E), membrane (M), and nucleocapsid (N). Protein S allows the virus to bind to the lining of the host cell. S-proteins have been found to be the target of angiotensin-converting enzyme 2 (ACE2) receptors in captive cells. The host structure then changes, allowing

Biosc Biotech Res Comm P-ISSN: 0974-6455 E-ISSN: 2321-4007

\section{crossef}

Identifiers and Pagination

Year: 2021 Vol: 14 No (7) Special Issue

Pages: 80-82

Commons License Attribn 4.0 Intl (CC-BY).

DOI: $h t t p: / / d x . d o i . o r g / 10.21786 / b b r c / 14.7 .19$
This is an open access article under Creative the genes to enter the institutional cell. Coronavirus, such as SARS and selected MERS. such as SARS-CoV-2 (critical coronavirus 2 respiratory infection); the previous temporary name was 2019- $\mathrm{nCoV}$, (Huang C et al., 2020).

Diagnosis: In patients with the disease, the disease may change within a week or more, starting with minor persistent symptoms (in some cases) to respiratory failure (Huang C et al., 2020). Many common complaints are fever (almost universal) and cough, possible or unproductive. Malgia and fatigue are common Intestinal symptoms (eg nausea, vomiting, diarrhea) are uncommon but may occur. A series of reported cases have no physical information, but physicians should pay special attention to the lung and hemodynamic symptoms of the disease. Patients with a serious illness may appear to be very ill, with tachypnea and difficulty breathing. The flu is

\section{Article Information}

Received: $13^{\text {th }}$ April 2021

ccepted after revision: $05^{\text {th }}$ June 2021 
common. Hypotension, tachycardia, and cold/ clammy restrictions suggest shock(Huang C et al., 2020).

Preventative:

1. Stay quarantine if you feelsick.

2. Maintain a safe distance between your hands and your eyes, nose, and mouth.

3. Hands should be washed often or for at least 20 seconds.

4. Maintain a healthy distance from someone who is coughing or sneezing.

5. When you sneeze, cover your nose and mouth with your bent elbow or a tissue.

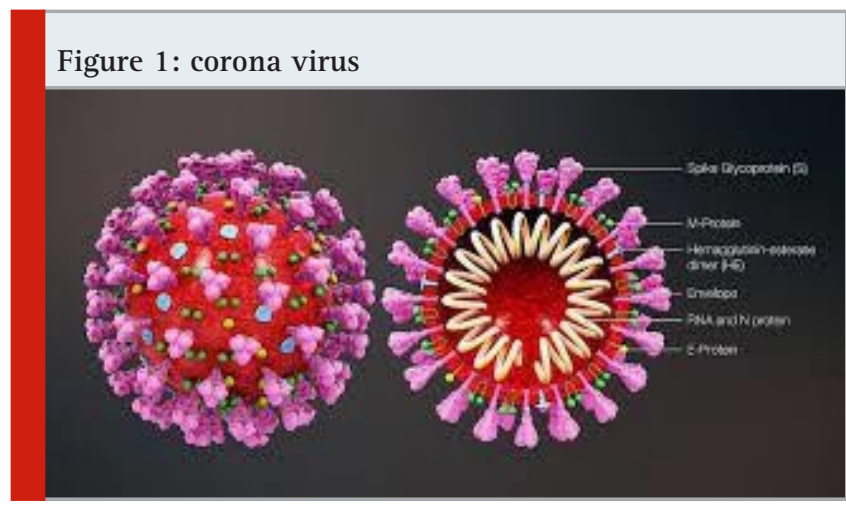

Physical examination

- Respiratory distress and shock can develop in symptomatic patients.

- $\quad$ Fever and cough are the most common symptoms.

- Myalgia and exhaustion are very common.

- Dyspnea patients with a moderate level of dyspnea

- A small number of patients have been confirmed to have hemoptysis.

- $\quad$ Chest pain that is pleuritic

- Symptoms of the upper respiratory tract

- Symptoms of a headache and stomach distress

- Serious disease patients may appear sick, with tachypnea and labored breathing. 6

- Fever is common, with temperatures frequently reaching 39 degrees Celsius. Fever does not grow in patients who are too old or have an immune deficiency.

- tachycardia, hypotension 11 year olds

- Changes in mental state6

- Tachycardia is a fast heart rate (Infants have a heart rate of more than 160 beats per minute, while older children have a heart rate of more than 150 beats per minute) or bradycardia is a condition in which a person's heart rate (In babies, the heart rate should be less than 90 beats per minute, and in older children, it should be less than 70 beats per minute.)7

- Tachypnea is a condition in which a person is unable to

- Purpura, petechiae, or mottled skin

- Oliguria is a condition characterized by a lack of thermia hyperthermia or hypothermia (hypothermia).

Clinical Characteristics: Upon the emergence of ARID, the corona-19 virus develops significantly from respiratory, dripping, respiratory failure and direct contact with a low rate of infection. However, on February 10th2020, a serious case at Sun Yat-Sen University, China was confirmed to have infected SARS corona virus 2 in the mouth of a pneumonia patient's mouth. Similarly, Zhang et al.9 be aware of the presence of SARS corona virus 2 in fecal and blood swabs, which raises the possibility of multiple transmission sites. ACE2 proteins are highly visible in lung alveolar epithelial cells and small intestinal enterocytes in large quantities, which can help determine the mechanisms of manifestation of infection and disease.10 Incubation period is 1-14 days, usually 3-7 days, depending on existing infectious disease research. Also, during delays, COVID-19 is contagious. It is very effective in people, especially the elderly and people with basic illnesses. The mean age for the patient is 47-59 years, and 41.9-45.7 percent was female. As SARS corona virus 2 is known, COVID-19 patients have shown similar symptoms, such as coughing, high fever, and feeling unwell. Often adolescents or a new generation with SARS corona virus 2 infection with flu-like symptoms and some patients are in a critical condition, rapidly developing ARDS, heart attack, multiple limbs, including death (Rakesh Kumar Jha et al., 2020).

Treatment Options: Several antiviral drugs are currently being tested in clinical trials. The FDA has approved lopinavir-ritonavir for the treatment of HIV infection. It has been used to treat other coronavirus infections, as well as SARS6 potency and MERS therapy. Some patients with COVID-19 in China are treated with this combination in combination with interferon alpha. A study comparing lopinavir-ritonavir with standard treatment in 199 patients with COVID-19. There was no significant difference in the time it took for patients to recover or die within 28 days, or for the length of viral RNA in oropharyngeal specimens. 8 In China and South Korea, chloroquine and derivatives have been used, with good results when combined with hydroxychloroquine in some cases.9 Remdesivir, an anti-viral agent with significant in vitro activity against coronaviruses, has been investigated (Rakesh Kumar Jha et al., 2020).

Screening Criteria: The VRIC has arranged for a temporary detection of SARS HIV by ancient Koch postulates and observing its morphology using electron microscopy. To date, the clinical diagnostic tool of COVID-19 gold detection of nucleic acid by real-time PCR in a nasal and throat nasal sample, with additions confirmed in the next generation sequence.10,11 A number of related studies were reported 12-16. Different Covid studies in this region were reviewed 17-20.

\section{CONCLUSION}

The emergence of COVID-19 quickly swept through China and increased in more than 180 countries outside of China from March 30th2020. Scientists have made great strides in diagnosing the new corona virus, and they are actively working on bacterial infections and vaccines. The following is a summary of current HIV information for SARS 2: First, emerging pneumonia, 
COVID-19, caused by SARS corona virus 2, has a higher rate of infection but is less aggressive than SARS and MERS in relation to illness and death. Second, people with disabilities include the elderly and others who need special care and treatment because of their health condition. Thirdly, supportive therapies, as well as strong antiretroviral drugs such as remdesivir, chloroquine or lopinavir / ritonavir, have had a clear effect on COVID-19 patients, while strong results have been obtained from other therapies.

\section{REFERENCES}

A Trial Of Lopinavir-Ritonavir In Adults Hospitalized With Severe Covid-19. N Engl J Med. Epub, 2020.

Acharya, Sourya, Samarth Shukla, And Neema Acharya (June 2020). Gospels Of A Pandemic- A Metaphysical Commentary On The Current Covid-19 Crisis.” Journal Of Clinical And Diagnostic Research 14, No. 6: 0a01-2. Https://Doi.Org/10.7860/Jcdr/2020/44627.13774.

Agostini Ml et al 2018. Coronavirus Susceptibility To The Antiviral Remdesivir (Gs-5734) Is Mediated By The Viral Polymerase And The Proofreading Exoribonuclease. Mbio. 9(2).

Arabi Ym et al (2018). Treatment of Middle East Respiratory Syndrome With A Combination of Lopinavir-Ritonavir And Interferon- $₫ 1 \mathrm{~b}$ (Miracle Trial): Study Protocol For A Randomized Controlled Trial. Trials. 19(1):81.

Arora, Devamsh, Muskan Sharma, Sourya Acharya, Samarth Shukla, And Neema Acharya (October 26, 2020). India In 'Flattening The Curve' Of Covid-19 Pandemic - Triumphs And Challenges Thereof." Journal Of Evolution Of Medical And Dental SciencesJemds 9, No. 43: 3252-55. Https://Doi.Org/10.14260/ Jemds/2020/713.

Bawiskar, Nipun, Amol Andhale, Vidyashree Hulkoti, Sourya Acharya, And Samarth Shukla (November 16, 2020). Haematological Manifestations Of Covid-19 And Emerging Immunohaematological Therapeutic Strategies." Journal of Evolution of Medical And Dental Sciences-Jemds 9, No. 46: 3489-94. Https://Doi. Org/10.14260/Jemds/2020/763.

Breakthrough: Chloroquine Phosphate Has Shown Apparent Efficacy In Treatment Of Covid-19 Associated Pneumonia In Clinicalstudies [Letter To The Editor]. Bioscience Trends. 14(1), 2020

Butola, Lata Kanyal, Ranjit Ambad, Prakash Keshaorao Kute, Roshan Kumar Jha, And Amol Dattaroa Shinde (September 28, 2020). The Pandemic Of 21st Century - Covid-19." Journal Of Evolution Of Medical And Dental Sciences-Jemds 9, No. 39: 2913-18. Https://Doi. Org/10.14260/Jemds/2020/637.

Cdc: Coronavirus Disease 2019 (Covid-19) Situation
Summary. Cdc Website. Updated March 26, 2020. Reviewed March 26, 2020. Accessed March 27, 2020. Https://Www.Cdc.Gov/Coronavirus/2019-Ncov/ Casesupdates/Summary.Html

Centers For Disease Control And Prevention: Human Corona Virus Types. (2020). Accessed: March11, 2020: Https://Www.Cdc.Gov/Coronavirus/Types.Html.

Clinical Pharmacology Powered By Clinical Key: Azithromycin. Clinical Key Website. Updated. Accessed March 27, 2020. Https://Www.Clinicalkey.Com/\#!/ Content/Drug_Monograph/6-S2.0-53

Godhiwala, Parth, Sourya Acharya, Gaurav Jagtap, Arvind Bhake, And Samarth Shukla (February 8, 2021). Leukemoid Reaction In A Covid-19 Patient." Journal Of Evolution Of Medical And Dental SciencesJemds 10, No. 6: 399-400. Https://Doi.Org/10.14260/ Jemds/2021/88.

Huang C et al (2020): Clinical Features Of Patients Infected With The 2019 Novel Coronavirus In Wuhan, China. Lancet. Epub.

Khatib, N., S. Gaidhane, A. Gaidhane, And Zahiruddin Quazi Syed (February 1, 2014). M-Health Intervention For Type Ii Diabetes Mellitus Patients In Indian Rural Areas." Diabetes Technology \&t Therapeutics 16, No. 1: A95-96.

Rakesh Kumar Jha, Pradip Jain, Ranjit S. Ambad, Nandkishor (2020). The Origin, Transmission And Mortality Of Corona Virus. Jcr;7(10):93-96. Doi:10.31838/ Jcr.07.10.23

Role Of Lopinavir/Ritonavir In The Treatment Of Sars: Initial Virological And Clinical Findings. Thorax. 59(3):252-6, 2004

Singhal, S., Zahiruddin Quazi Syed, S. N. Mahajan, S. K. Diwan, And A. Gaidhane (December 2009). Reasons For Non-Compliance Among Patients Treated Under Revised National Tuberculosis Control Programme (Rntcp) And Their Treatment Outcome After Structured Counselling." Asian Pacific Journal of Tropical Medicine 2, No. 6: 48-51.

Spoorthy, Mamidipalli Sai, Sree Karthik Pratapa, And Supriya Mahant ((June 2020)). Mental Health Problems Faced By Healthcare Workers Due To The Covid-19 Pandemic-A Review.” Asian Journal Of Psychiatry 51. Https://Doi.Org/10.1016/J.Ajp.2020.102119.

Wanjari, A. K., Ayush Dubey, Sourav Chaturvedi, And Sunil Kumar ((August 2020)). Young Covid 19 Presenting As Fatal Subarachnoid Hemorrhage: Association Or Chance?" Medical Science 24, No. 104: 2712-15.

Zhang L, Shen Fm, Chen F, Lin Z (2020). Origin And Evolution Of The 2019 Novel Corona Virus. Clin Infect Dis. Https://Doi.Org/10.1093/Cid/Ciaa112. 